\title{
Discrimination of lithium and sodium chloride solutions by rats ${ }^{1}$
}

\section{CHARLES STROM, ANN LINGENFELTER, and J. F. BRODY, University of Pittsburgh, Pittsburgh, Pa. 15213}

Earlier workers found that rats could not discriminate between equimolar lithium chloride and sodium chloride solutions in either successive or simultaneous discrimination paradigms. The present studies reveal that rats can discriminate between the two solutions in a simultaneous discrimination paradigm and indicate that, in the successive situation, a high degree of stimulus generalization may be occurring rather than a failure of discrimination.

If rats drink lithium chloride $(\mathrm{LiCl})$ solution, symptoms of illness will result, and the rats will drink very little $\mathrm{LiCl}$ on future presentations. Furthermore, the avoidance behavior will generalize to sodium chloride $(\mathrm{NaCl})$ solutions of identical molarity in both simultaneous and successive discrimination paradigms (Nachman, 1963). Nachman's data imply that equimolar solutions of $\mathrm{NaCl}$ and $\mathrm{LiCl}$ cannot be discriminated by rats even in the best of conditions.

However, Beidler (1953) found that applying $\mathrm{LiCl}$ to the rat's tongue produced $10 \%$ more activity in the chorda tympani than did applying equimolar solutions of $\mathrm{NaCl}$. Fishman (1957) also found a slight difference in the response evoked by $\mathrm{NaCl}$ and $\mathrm{LiCl}$ in single fibers of the chorda tympani. One would assume that these differences in evoked activity have informational value, i.e., that rats can discriminate between $\mathrm{LiCl}$ and $\mathrm{NaCl}$. Thus, neurophysiological evidence shows differences in neural activity evoked by the two solutions but the behavioral data suggest that these differences are of no use to the rat. There is current interest in $\mathrm{LiCl}$ and $\mathrm{NaCl}$ as tools for the investigation of learning phenomena (Garcia \& Koelling, 1966), and there is a great interest in correlating neural activity with overt behavior. Consequently, the ability of rats to discriminate between $\mathrm{NaCl}$ and $\mathrm{LiCl}$ was reinvestigated.

In preliminary work, we verified Nachman's findings with a successive discrimination task. After a habituation period in which the rats were trained to drink during daily 20-min sessions, the animals were given $.12 \mathrm{M} \mathrm{LiCl}$ on even-numbered days and tap water on odd-numbered days. After three presentations of $\mathrm{LiCl}$, the rats would drink neither the $\mathrm{LiCl}$ nor . $12 \mathrm{M} \mathrm{NaCl}$. Rats with no earlier experience with $\mathrm{LiCl}$ readily drank the $\mathrm{NaCl}$. Thus, in a successive discrimination paradigm, the rats did generalize from $\mathrm{LiCl}$ to $\mathrm{NaCl}$. Cowey (1968) states that when cues are highly similar, animals are more likely to be successful in a simultaneous discrimination task than they are in a successive paradigm. Therefore, our next tests were run with a simultaneous discrimination situation, and it is these data that are the subject of this paper.

\section{SUBJECTS}

Male Sprague-Dawley rats (300-350 g) were used as Ss. All 10 animals were experimentally naive.

\section{APPARATUS}

The animals were housed in wire cages, $14 \times 7 \times 7$ in., that were mounted in a multi-cage rack. Eight-ounce bottles with metal drinking tubes were used to present the solutions. The tube extended into the cage $1 / 2$ in. When two solutions were presented, the tubes were approximately 2 in. apart and 1 in. above the cage floor. The rats were fed Wayne Lab Blox ad lib. PROCEDURE

Two bottles were mounted on each cage. One bottle contained $50 \mathrm{ml}$ of $\mathrm{NaCl}$ and the other contained $50 \mathrm{ml}$ of $\mathrm{LiCl}$. Both solutions were $.12 \mathrm{M}$ concentration. Every $24 \mathrm{~h}$, the fluid remaining in the bottles was measured and the bottles were refilled to

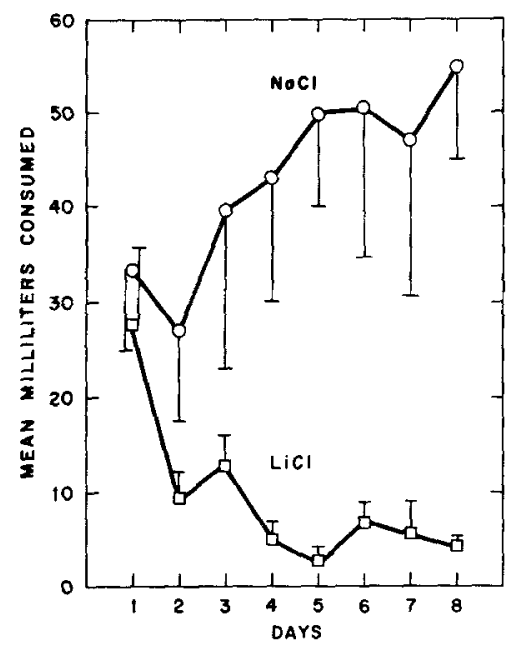

Fig. 1. Mean daily consumption of $.12 \mathrm{M}$ refuse to drink in the test cage with few $\mathrm{NaCl}$ and $.12 \mathrm{M} \mathrm{LiCl}$ by 10 rats. Brackets aversive consequences. Nachman's animals represent one standard deviation. the 50-ml level. The relative positions of the two solutions on the cages was varied daily in a predetermined random order. Preliminary work indicated that fluid loss due to mounting and removing the bottles varied nonsystematically between 3 and $7 \mathrm{ml}$.

\section{RESULTS AND DISCUSSION}

Figure 1 presents the mean daily intake of $\mathrm{LiCl}$ and $\mathrm{NaCl}$. All comparisons between the two lines are significant ( $p$ less than .01 , t test) except for the Day 1 consumption. Clearly, the rats could discriminate between the two solutions when they were present simultaneously. It is possible that the animals were sampling the fluids randomly and using aversive feedback as a cue for further drinking. An additional experiment was run to assess this possibility. Naive rats were given 20-min exposure to $\mathrm{LiCl}$ and $\mathrm{NaCl}$ on Day 5 (Days 1-4 were used to habituate the animals to the drinking regimen) and then allowed only 4 min to drink on Days 6-9. Under these conditions, the animals still drank significantly more $\mathrm{NaCl}$ than $\mathrm{LiCl}$. The rats were carefully observed, and it was noted that the animals "sampled" the solutions by taking one or two drops from the spout. They then invariably chose the $\mathrm{NaCl}$ over the LiCl. Apparently, the mechanism for discrimination of the two fluids provides relatively immediate information to the animal. Although the use of cues from aversive feedback cannot be ruled out, it would appear that these cues are not of critical importance to the discrimination.

Nachman (1963) also used a simultaneous discrimination paradigm but found little or no evidence for discrimination. His animals received $\mathrm{NaCl}$ and $\mathrm{LiCl}(.12 \mathrm{M})$ for $10 \mathrm{~min}$ for each of 5 days. The rats drank, on the average, $2.4 \mathrm{ml}$ of $\mathrm{NaCl}$ and $1.5 \mathrm{ml}$ of $\mathrm{LiCl}$ per session. Nachman felt that the small difference in favor of $\mathrm{NaCl}$ was not due to discrimination of the solutions.

It is not possible to be certain of the reasons for the difference between our findings and those of Nachman (1963); however, certain variations in our procedures appear responsible. In the present studies, the only liquid available to the rats was given in the test situation. The animals were forced to drink in order to live. Nachman, on the other hand, made an operational distinction between his home-cage and testing situations by using a separate cage to present $\mathrm{LiCl}$ or $\mathrm{NaCl}$. After testing was over, the rats were given approximately $50 \mathrm{~min}$ of access to water in their home cages. Thus, the rat could aversive consequences. Nachman's animals
had received 20 days of experience with 
$\mathrm{NaCl}$ and $\mathrm{LiCl}$ under these conditions before the simultaneous discrimination test was run. It may be that, by Day 20 , the rats were trained not to drink rather than perform a difficult discrimination. The use of separate test and home cages would be expected to favor the development of a "nondrinking" discrimination.

There are several implications of the present work. First, the performance of a discriminative response depends upon both the presence of cues and appropriate $r e$ inforcement contingencies. Discrimination paradigms must be examined carefully to be certain that a failure of a discriminative response to appear can be attributed to the absence of cues rather than to the reinforcement contingencies. Second, the avoidance of $\mathrm{NaCl}$ solutions after experience with $\mathrm{LiCl}$ solutions could be due to failure of discrimination or to generalization of the avoidance behavior. It would appear that the second interpretation is more likely.

\section{REFERENCES}

BEIDLER, L. M. Properties of the chemoreceptors of the tongue of the rat. Journal of Neurophysiology, 1953, 16, 595-607.

COWEY, A. Discrimination. In L. Weiskrantz (Ed.) Analysis of behavioral change. New York: Harper \& Row, 1968. Pp. 189-238.

FISHMAN, I. Y. Single fiber gustatory impulses in the rat and hamster. Journal of Comparative Physiology, 1957, 49, 319-334.

GARCIA, J., \& KOELLING, R. A. Relation of cue to consequence in avoidance learning. Psychonomic Science, 1966, 4, 123-124.

NACHMAN, M. Learned aversion to the taste of lithium chloride and generalization to other salts. Journal of Comparative \& Physiological Psychology, 1963, 56, 343-349.

$$
\text { NOTES }
$$

1. These studies were executed in an experimental psychology laboratory taught by the third author and were subjected to two independent replications. Thanks are due to Dr. James Voss, Department Chairman, for agreeing that "real experiments" could be done in a teaching/learning situation.

2. Send reprint requests to J.F. Brody, Department of Psychiatry, Yale University Medical School, 34 Park St., New Haven, Conn. 06508 .

\section{Number of training trials and frustration effects of nonzero reward reduction in the double alley}

RICHARD L. PATTEN and DAVID B. MYERS, Iowa State University, Ames, IOWa 50010

$A$ double runway was employed to examine the possibility that nonzero reduction of reward in the first goalbox (BI) leads to frustration effects in the form of energized running in the second runway. Groups of rats were given 12 or 72 rewarded runs to eight pellets in $B 1$ prior to receiving a test phase of 24 trials, which included 12 trials on which a single BI pellet was available. Significant interactions between number of preshift rewards and FE magnitude in both start - and run-speed measures provided evidence for frustration effects of nonzero reward reduction.

According to the Amsel (1958)-Spence (1960) frustration theory, nonreward (F trial) of a previously rewarded response produces a frustrative increment in an organism's drive level. In the familiar supported this assumption by showing that the difference between $A 2$ running speeds on B1 reward and B1 nonreward trials (designated FE) is greater in Ss having 60 prior B1 rewards than in Ss having 12 B1 rewards.

Although part of the FE may be due to hunger differences on B1 reward and Bl nonreward trials, the Yelen (1969) results point to involvement of a conditioning factor in producing the FE. The present experiment-similar in design to the Yelen (1969) study-provided the same sort of support for a frustration interpretation of $\mathrm{FE}$ produced by nonzero $B 1$ reward reduction.

\section{METHOD}

The Ss were 24 naive male hooded rats, 110-120 days old at the start of the experiment.

The apparatus was a flat-black L-shaped double runway, $4 \frac{13}{2} \mathrm{in}$. high and $3 \frac{3}{4} \mathrm{in}$. wide throughout. A 13-in. startbox led into $A 1$, which was 60 in. long and terminated in a 16-in. goalbox. The 8-in. right-angled foot of B1 led to the A2 start-door. A2 was 76 in. long. Startbox, runway, and goalbox sections of the apparatus were defined by opaque sliding doors. Metal measuring spoons, $1 \mathrm{in}$. in diam, protruded from the end of $\mathrm{B} 1$ and $\mathrm{A} 21 / \mathrm{1} / \mathrm{in}$. above the floor and served as foodcups. A small 6.3.V ac lamp over the foodcup illuminated B1. The apparatus was illuminated by dim, diffuse fluorescent room lighting. Ss were permitted entry into $\mathrm{A} 2$ within a minimum of $13 \mathrm{sec}$ after eating in $\mathrm{B} 1$, which included $10 \mathrm{sec}$ plus $3 \mathrm{sec}$ orientation toward the A2 door. This procedure was designed to approximate the 15 -sec value that appears to be optimal for FE (MacKinnon \& Amsel, 1964).

When the start-door to A2 was opened, an electronic clock started. Sequential interruption of photobeams 2 in. and 14 in. from the A2 start-door operated electronic clocks, providing start and run time measures over 2-in. and 12-in. segments of $\mathrm{A} 2$.

Two weeks prior to the start of experimental training, Ss were placed on a diet of $10 \mathrm{~g} /$ day of lab chow until each S's weight dropped to $77 \%$ of his preexperimental weight. Twenty-four Ss were assigned randomly to two experimental groups, which received 12 (Group 12) or 72 (Group 72) rewarded training trials at the rate of four trials/day. All Ss received eight .045 -g Noyes pellets in B1 and three pellets at the end of $A 2$. After the preshift training, Ss were shifted to a $50 \%$ schedule of $\mathrm{B} 1$ reward reduction for 24 trials. During the reduction phase, half of each day's trials were to eight B1 pellets and half were to one B1 pellet according to the following six four-trial 